\title{
Unravelling the hydrocarbon charge process by using microscopic fluorescence technique — a case study from Dina 2 condensate gasfield in Kuqa depression, western China
}

\author{
Hai Wu ${ }^{1}$, Shaobo LiU ${ }^{1}$, Qingong Zhuo ${ }^{1}$, Xuesong
} $\mathrm{LU}^{1}$

${ }^{1}$ Research Institute of Petroleum Exploration and Development, PetroChina, Beijing 100083, China

Corresponding author E-mail address:wuhai2012@hotmail.com

The hydrocarbon charging history of Dina 2 area of Kuqa Depression is systematically analyzed based on quantitative grain fluorescence, fluid inclusion and laser raman spectroscopy, and the hydrocarbon accumulation process of Dina 2 condensate gas reservoir is discussed by combining the hydrocarbon charging history with the burial history, thermal history, hydrocarbon generation history and trap formation history. The QGF index of the tested reservoir samples is all greater than 4, and the QGF-E intensity is more than 20PC when depth is less than $5057 \mathrm{~m}$. Combined with the results of core analysis, it is determined that the present residual oil/water interface locates at about $5057 \mathrm{~m}$ According to inclusion petrography, temperature data and authigenic illite $\mathrm{K}-\mathrm{Ar}$ dating data, it is held that the reservoir experienced three stages of hydrocarbon charging: In the first stage, heavy oil was charged at the end of Oligocene( about $23.53 \mathrm{Ma})$, but it escaped because of the lack of cap rock. In this period, quartz minerals had not entered into the rock cementation stage for the shallow burial depth and low formation temperature of reservoir, therefore the oil charge could not be recorded in this stage. In the second stage( $8 \sim$ $5 \mathrm{Ma}$ ), the strong fold of strata caused by the Neogene Himalaya orogeny lead to the forming of a large numbers of traps, in which the light hydrocarbon from the Qiakemake Formation source rock of middle to lower Jurassic and the Huangshanjie Formation source rock of Triassic accumulated - In this stage, the hydrocarbon charging time lasted for a long period, and the inclusions are dominated by blue-green and blue color fluorescence. In the third stage, natural gas charged into the reservoir from late Pliocene $(2.5 \mathrm{Ma})$, which changed the components of the hydrocarbons formed in the early time, and the present Dina 2 condensate gas field was formed.

Key Words : quantitative grain fluorescence, fluid inclusion, authigenic illite $\mathrm{K}-\mathrm{Ar}$ dating, foreland basin, condensate gasfield 